\title{
GASTROESOPHAGEAL REFLUX DISEASE: TREATMENT OPTIONS ARE BEYOND THE PROTON PUMP INHIBITORS.
}

1. MBBS, FCPS

Associate Professor Medicine Al-Tibri Medical College, Isra University Karachi Campus.

2. MBBS, MRCP, FCPS, FRCP

Professor Medicine

Dow University of Health Science Karachi.

3. MBBS, FCPS

Assistant Professor Medicine Chandka Medical College Larkana

4. MBBS

Family Physician

Zayed Military Hospital UAE.

5. MSc

Research Officer

Al-Tibri Medical College,

Isra University Karachi Campus.

Correspondence Address:

Dr. Abdul Rabb Bhutto

Department of Medicine

Al-Tibri Medical College,

Isra University Karachi Campus,

Old Thana, Gadap town, Malir,

Karachi.

drbhuttoarabb@yahoo.com

Article received on:

05/08/2019

Accepted for publication:

$26 / 11 / 2019$

\author{
Abdul Rabb Bhutto', Amanullah Abbasi ${ }^{2}$, Sultan Ahmed Chandio ${ }^{3}$, Aftab Ahmed Lolai ${ }^{4}$, \\ Muhammad Arsalan ${ }^{5}$
}

ABSTRACT... Objectives: To observe the effects of different combinations of medicines in GERD patients by using FSSG score. Study Design: Observational Study. Setting: Al-Tibri Medical College Hospital, Isra University Karachi Campus Karachi. Period: June 2017 to December 2017. Material \& Methods: The study was conducted on GERD patients at Tertiary Care Hospital of Karachi. Adult patients from male and female gender with clinical symptoms suggestive of GERD were included. All 154 eligible patients enrolled in the study and divided into three groups Group I (PPI alone), Group II (PPI with prokinetic) and Group III (PPI, prokinetic and SSRI). After 2 weeks of treatment, FSSG score of every participant was calculated. Results: Results of 134 patients 72 (53.3\%) males and 63 (46.7\%) females were analyzed. The cumulative mean age was $37.12 \pm 8.221$ (range $16-60$ ) years. The patients were grouped by single blind randomization method, each group I and group II consisted of 45 subjects and 44 patients were enrolled in group III. The mean FSSG score prior to treatment and after treatment was $21.194 \pm 4.786$ and $14.962 \pm 3.696$ respectively, hence, the gradient of pre-treatment and post-treatment was $6.231 \pm 4.601$. The three groups shown significant improvement in FSSG score after treatment but the group III had shown highest improvement in mean FSSG score of 7.522 \pm 3.592 , followed by group II with 7.2889 $\$ 3.805$ and group I had shown the lowest improvement of $3.911 \pm 5.346$ but statistical analysis revealed these improvements within each group as insignificant while turned to be significant when groups were analyzed with each other. ( $p$ 0.003). Conclusion: The results of this study suggests that PPIs alone have good therapeutic role but as dysmotility aspect of GERD and psychological comorbidity is very common in those patients and is likely to play an important role in response, or failure of response, to proton pump inhibitor treatment. Hence, addition of prokinetic and anxiolytics can augment the response rate.

Key words: $\quad$ Cinitapride, Dysmotility Aspect, Ecitalopram, FSSG, GERD.

Article Citation: Bhutto AR, Abbasi A, Chandio SA, Lolai AA, Arsalan M. Gastroesophageal reflux disease: Treatment options are beyond the proton pump inhibitors. Professional Med J 2020; 27(7):1401-1407.

DOI: 10.29309/TPMJ/2020.27.07.4008

\section{INTRODUCTION}

Gastroesophageal reflux disease (GERD) and Dyspepsia syndrome are universally prevalent disorders. ${ }^{1}$ The prevalence of GERD varies greatly with ethnicity and geography; $18.1-27.8 \%$ in North America, $23.0 \%$ in South America, $8.8-25.9 \%$ in Europe, $11.6 \%$ in Australia and $8.7-33.1 \%$ in the Middle East with lower prevalence was found in East Asia region, ranging from 2.5 to $7.8 \%{ }^{2}$ Several studies in Iranian population reported the prevalence of GERD was 6.3-18.3\%, while in Pakistan a study showed higher prevalence, $24.0 \% .^{3-4}$
GERD is defined as a pathological condition characterized by excessive reflux of gastric contents into the esophagus and giving rise variety of symptoms..$^{5-6}$ Clinically, patients can present with either esophageal or extra esophageal symptoms like reflux, cough chest pain, hoarseness, sleep disturbances, dental erosions and asthma. ${ }^{7}$ If untreated, GERD may lead to complications like esophageal ulceration, stricture, Barrett's esophagus and development of adenocarcinoma. ${ }^{8}$ Moreover, in GERD, general health like social, emotional, functioning and physical activities are also affected and leading to poor quality of life. ${ }^{9}$ 
Clinically, GERD is usually diagnosed by some combination of presenting symptoms, ambulatory reflux monitoring, upper gastrointestinal (Gl) endoscopy and response to anti secretory treatment. Although, the standards of diagnosis of GERD is endoscopic examination of upper Gl tract but there are certain limitations encountered to implement this diagnostic tool like the experts and facilities are not widely available and procedure itself is not acceptable and /or less comfortable for most of the patients. Moreover, it is also not logical to have a repeat a procedure for the purpose of only treatment response assessment. Hence, there are certain questionnaires or scoring systems have been designed for the screening of GERD and assessment of its therapy. ${ }^{10}$ Among those, a questionnaire, Frequency Scale for the Symptoms of GERD (FSSG) is 12 questions containing scoring questionnaire has been developed in Japan ${ }^{11}$ for evaluation of GERD symptoms, among those 12 questions five questions are related to dysmotility/dyspepsia and seven questions for reflux.

In clinical practice, most patients of GERD are managed in general practice and the treatment is primarily focused on symptomatic relief with PPIs. However, despite the PPIs have clear therapeutic benefits; the prevalence of PPI failure in clinical practice may reach $30 \% .{ }^{12}$ Furthermore, due to its chronicity, recurrent course and wide variety of common associated risk factors like smoking ${ }^{13}$, body mass index $(\mathrm{BMI})^{14,15}$, alcohol $^{15}$, use of aspirin and non-steroidal anti-inflammatory drugs ${ }^{14}$, social deprivation ${ }^{13}$, psycho-somatism ${ }^{14-15}$ and family history of upper gastrointestinal (Gl) disease ${ }^{14-15}$ the effective management of GERD remains a challenge for treating physicians.

The aim of this study was to evaluate and compare the efficacy of PPI with combinations of prokinetic and/or anxiolytic therapies for GERD.

\section{MATERIAL \& METHODS}

This observational study was conducted on patients visited outpatient department of Al-Tibri Medical College Hospital, Isra University Karachi from June 2017 to December 2017. Adult patient's male and female with symptoms suggestive of
GERD like heartburn (burning sensation/pain in the chest) and / or regurgitation (acid/bitter taste to the tongue) and willing to participate in study were included in the study. Patients with chronic diseases like chronic liver disease, uncontrolled diabetes mellitus, malignancy and previous or current psychiatric illness or drugs usage were excluded from the study.

Written informed consents were taken from patients and the approval of the study was obtained from institutional ethics committee. For the implementation of inclusion and exclusion criteria, all subjects underwent a process of detailed clinical history, thorough physical examination, routine laboratory investigations, in included patients, more specific investigations imaging, endoscopy and/or histopathology were done. Upper Gl endoscopy was not done in every patient but some patients underwent the procedure, either before enrollment in study as a part of their symptoms workup or we did the procedure in selected/doubtful cases to fulfill exclusion criteria. During clinical history subjects were interviewed to response to symptoms frequency of FSSG questionnaire ranging from 0 to 4 and every question has scoring as follows: never $=0 ; \quad$ occasionally $=1 ; \quad$ sometimes $=2$; often $=3$; and always $=4$.

All 154 eligible subjects were divided in to three groups Group I, Group II and Group III by using Randomization method.

Group I, has been advised Omeprazole $20 \mathrm{mg}$ per oral twice a day for 2 weeks, Group II, Omeprazole $20 \mathrm{mg}$ per oral twice a day with cinitapride1 $\mathrm{mg}$ per oral thrice a day for 2 weeks and Group III was assigned to combination of Omeprazole 20 $\mathrm{mg}$ per oral twice a day, cinitapride $1 \mathrm{mg}$ per oral thrice a day and Ecitalopram $10 \mathrm{mg}$ per oral once daily for two weeks. After 2 weeks of treatment, FSSG score of every participant was calculated again by same interviewer. Both the investigator and study subjects were unaware about the treatment received by each group via double blind strategy, until the end of study when code was opened. 
All the data were recorded in the entry form and study results were input and analyzed using Statistical Package for the Social Sciences (SPSS) 23.0 for windows. Descriptive statistics were presented in mean \pm SD for numerical data while categorical data were presented in proportion (\%). Total FSSG score was calculated by addition of all scores for each question in the FSSG questionnaire before and after treatment. The paired t-test was used to analyze improvement in FSSG score within each group while $F$ test was used to analyze any difference among all three groups. Statistically significant was determined by p-value under 0.05 with $95 \%$ confidential interval $(\mathrm{Cl})$.

\section{RESULTS}

Initially, 183 patients were assessed for eligibility of participation in study but the results of 134 subjects were available for final analysis (29 excluded/withdrawn due to different reasons while 20 subjects were missed/lost follow up) as shown in Figure-1. Among those, 72 (53.3\%) were males and $63(46.7 \%)$ were females. The cumulative mean age was37.12 \pm 8.221 (range 16 - 60) years with gender based mean age was almost identical (37.03 \pm 7.885 years for females and $37.22 \pm 8.646$ years for males). Following randomization, each group I and group II consisted of 45 subjects each while 44 patients were fallen in group III. According to racial distribution of subjects, the majority belonged to Sindhi 54 (40.30\%), followed by Pathan 28 (20.89\%), Urdu 26 (19.40\%), Baloch 12 (8.95\%), Punjabi 11 (8.20\%) and 03 (2.24\%) subjects were of Kashmiri origin. The demographic data and FSSG score of all three groups were shown in Table-I.

The both FSSG scores prior to and post treatment of 134 subjects were analyzed and revealed the mean score of $21.194 \pm 4.786$ and $14.962 \pm 3.696$ respectively; hence, the gradient of pre and post treatment was $6.231 \pm 4.601$. According to group based distribution, all three groups shown improvement in FSSG score after treatment but the group III has shown highest improvement in mean FSSG score of $7.522 \pm 3.592$, followed by group II with $7.2889 \pm 3.805$ and group I had 3.911 \pm 5.346 . Although, all three group revealed lower post treatment FSSG scores as compare to their respective pre-treatment scores but turned to be statistically insignificant as shown in TableII, while analysis of Groups with each other came out with the difference of mean improvement in post treatment were found statistically significant (0.003) as shown in Table-III.

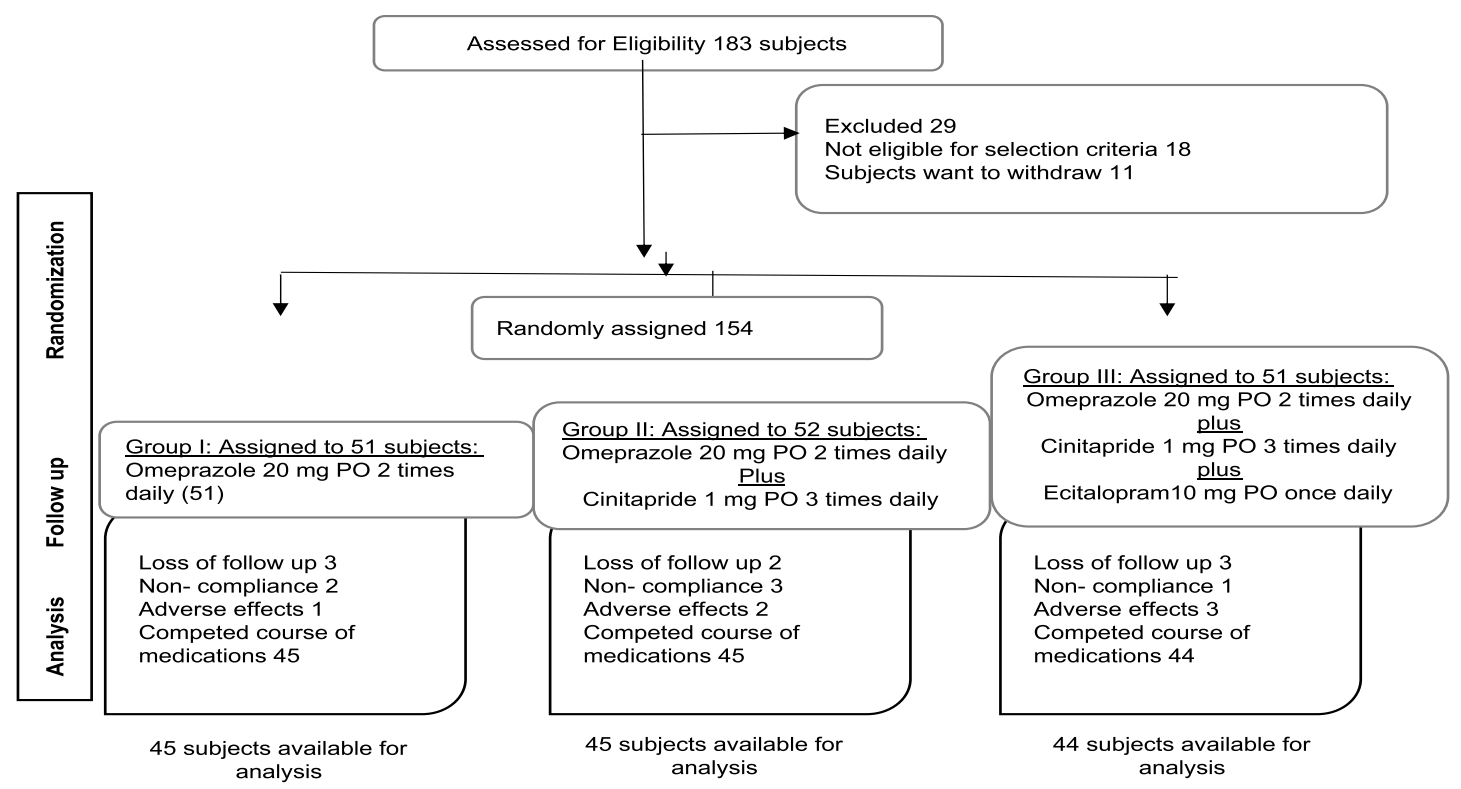

Figure-1. Assessment, randomization, follow up and analysis of study subjects. 


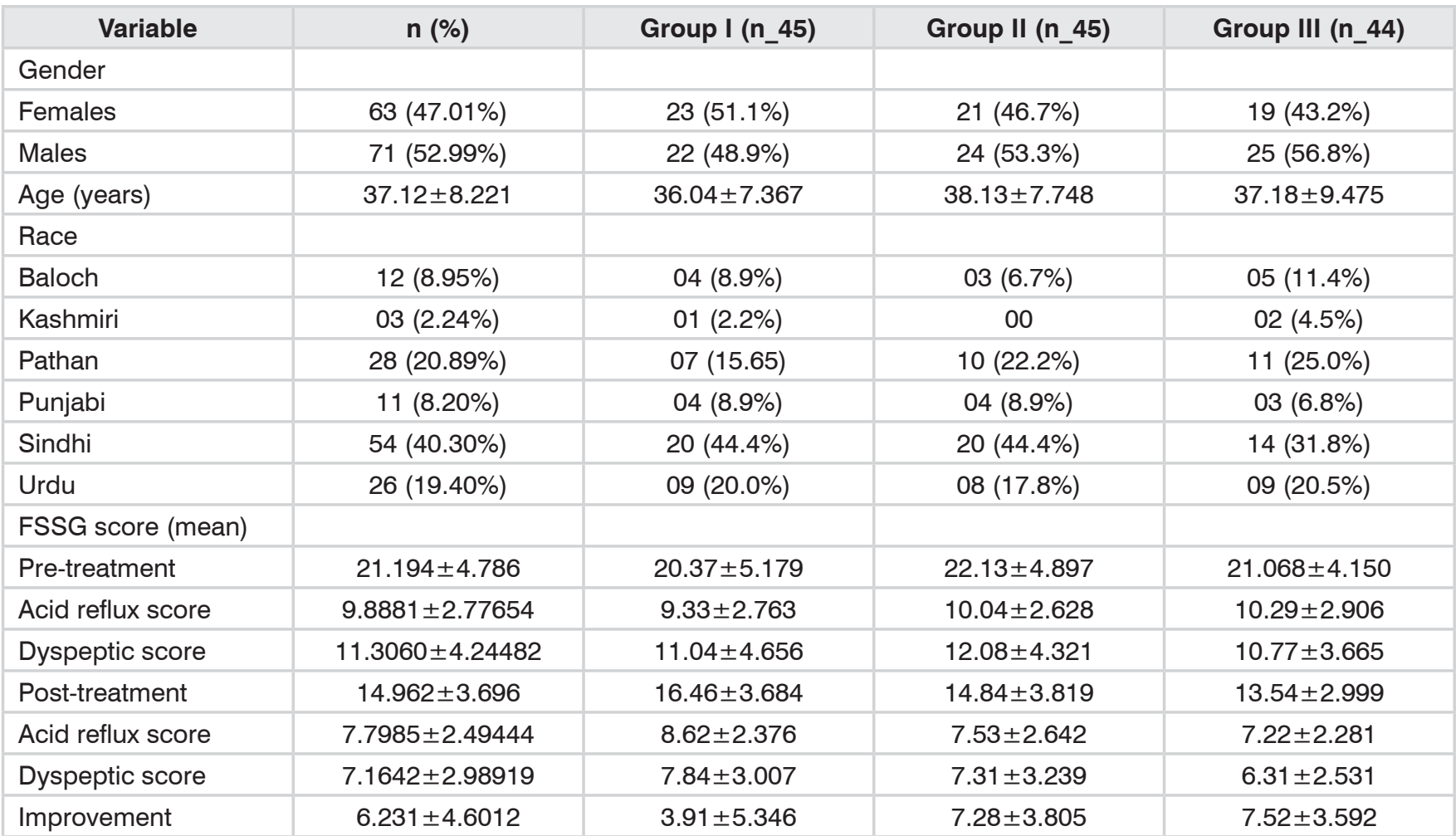

Table-I. Basic demographics of study population

\begin{tabular}{|l|c|c|c|c|}
\hline \multicolumn{1}{|c|}{ Group } & Pre-treatment & Post treatment & Means improvement & P-Value \\
\hline Group I & $20.3778 \pm 5.1799$ & $16.466 \pm 3.684$ & $3.911 \pm 5.346$ & 0.378 \\
\hline Group II & $22.133 \pm 4.897$ & $14.844 \pm 3.819$ & $7.2889 \pm 3.805$ & 0.988 \\
\hline Group III & $21.068 \pm 4.150$ & $13.545 \pm 2.999$ & $7.522 \pm 3.592$ & 0.99 \\
\hline
\end{tabular}

Table-II. Group based results of pre-treatment, post treatment and mean improvement in FSSG score of study subjects

\begin{tabular}{|l|c|c|c|c|}
\hline \multicolumn{1}{|c|}{ Group } & Pre-treatment & Post treatment & Means improvement & P-Value \\
\hline Group I & $20.3778 \pm 5.1799$ & $16.466 \pm 3.684$ & $3.911 \pm 5.346$ & \\
\hline Group II & $22.133 \pm 4.897$ & $14.844 \pm 3.819$ & $7.2889 \pm 3.805$ & 0.003 \\
\hline Group III & $21.068 \pm 4.150$ & $13.545 \pm 2.999$ & $7.522 \pm 3.592$ & \\
\hline
\end{tabular}

Table-III. Analysis of mean differences in FSSG score of study subjects

\section{DISCUSSION}

The diagnosis of GERD is not straightforward or easy due to its diverse clinical presentations. The traditional diagnostic tools of GERD such as endoscopy and barium swallow have a sensitivity of $30 \%$ to $50 \%{ }^{16-17}$ and $10 \%$ to $50 \%^{18}$ and respectively. Six to $15 \%$ of patients have normal results of 24-hour monitoring of esophageal $\mathrm{pH}$ with abnormal symptom index and does not widely available too. ${ }^{19}$ Hence, the lack of gold standard modality for diagnosis of GERD brought about certain questionnaires or scoring systems for not only its diagnosis but also assessment of response to its different therapies.

Validation of FSSG score against the endoscopic findings was assessed in Japan with the cut-off score at 8 , showed specificity $59 \%$, sensitivity of $62 \%$, and accuracy of $60 \% .20-21$ In our study, the mean pre-treatment FSSG score was $21.194 \pm 4.786$ and a bit lower than in the study conducted by Ndraha $(25.3 \pm 8.2)^{22}$ that could be explained by either longer duration of symptoms or higher mean age of subjects in Ndraha's 
study. Although the main therapeutic agent for GERD is PPI but in recent years addition of prokinetic agents have been tried to get higher response and studies have recommended the use of combination of both PPI and prokinetics especially in subjects with higher pre-treatment FSSG score. One theory that can explain this augmentation of response with addition of prokinetics to PPI thought to be instability of PPIs on low $\mathrm{pH}$ and delayed gastric emptying due to dysmotility leading to prolonged retention of PPIs inside the stomach that may consequently lead to instability of PPIs and their impaired acid suppression effects. Therefore, to achieve PPIs therapeutic benefits their rapid transit from stomach to upper intestine is mandatory that can be achieved with prokinetics. ${ }^{23}$ In this study improvement was found in mean FSSG score in both group I $(20.37 \pm 5.179 \rightarrow 16.46 \pm 3.684)$ and group II $(22.13 \pm 4.897 \rightarrow 14.84 \pm 3.819)$ but the improvement was higher in group II (7.28 \pm 3.805$)$ as compared to group I $(3.91 \pm 5.346)$ and supporting the previous studies recommendations of additional benefits of prokinetics to PPIs. But statistically, these improvements of Group I and Group II were not significant.

Moreover, third group in our study was subjects assigned to additionally SSRI and shown the highest improvement after treatment. The immune system and gastrointestinal tract are particularly affected by different stressors and this affect is evaluated by various studies. Faruqui $A$ in his study evaluated the efficacy and tolerability of fixed dose combination of amitriptyline and PPI in GERD associated with anxiety and found that symptoms and anxiety score reduced significantly $(P<0.0001)$ at week 4 compared to baseline. ${ }^{24}$

More recently, the researchers have focused on the relationship between reported GERD symptoms and stress. ${ }^{25}$ It has been observed that prolong exposure to life stressors may lead to development of GERD symptoms.

Objective measurements of acid reflux is not influenced by stress tasks ${ }^{25}$, but the reflux patients who were exposed to prolonged stressful stimuli and remained chronically anxious may be more likely to perceive low-intensity esophageal stimuli as painful reflux symptoms. Hence, the complaints of GERD symptoms could be triggered by even normal esophageal acid exposure. Moreover, it is psychological distress that could predispose the patient to have GERD manifestations rather specific psychiatric disorder should be blamed for gastrointestinal distress. ${ }^{26}$

Stress and GERD relation theory was further evidenced by Naliboff et $\mathrm{al}^{27}$, who found that heartburn symptom had most close correlation with vital exhaustion (measure of sustained stress symptoms) and Fass et $\mathrm{al}^{28}$ have observed that exacerbation of heartburn symptoms in GERD patients can be caused by acute auditory stress by enhancing perceptive response to intraesophageal acid exposure.

Yang et al have also found in their study that Anxiety and depression may play an important role in the occurrence of GERD and the Quality of Life (QoL) of patients with GERD is reduced by anxiety and depression. ${ }^{29}$

Although, the role of anxiolytics and antidepressants in GERD patients is still unknown and keeping a fact in mind regarding variety of side effects including dry mouth, blurred vision, urinary retention, constipation, nausea, sedation (with tricyclics), diarrhea, abdominal pain, loss of libido (with SSRIs) and erectile dysfunction; the low dose SSRI could be better option in GERD patients especially those with high FSSG score and/or the patients non-responders to PPIs and prokinetics or both.

There were few limitations of our study; first, single center based with limited sample size and representing of only one area of Karachi city, secondly, only FSSG questionnaire was used while other diagnostic modalities like endoscopy and 24-hour esophageal $\mathrm{pH}$ monitoring of all patients were not available.

\section{CONCLUSION}

The results of this study suggests that PPIs alone have good therapeutic role but as dysmotility aspect of GERD and psychological comorbidity 
is very common in those patients and is likely to play an important role in response, or failure of response, to proton pump inhibitor treatment. Hence, to tackle these two associated factors addition of prokinetic and anxiolytics can augment the response rate. Further studies are required to assess more about the efficacy and side effects of these agents especially anxiolytics, on larger scale and longer duration of treatment.

\section{Copyright@ 26 Nov, 2019.}

\section{REFERENCES}

1. Simadibrata M. Dyspepsia and gastroesophageal reflux disease (GERD): Is there any correlation? Acta Med Indones-Indones J Intern Med. 2009; 41(4): 222-7.

2. El-Serag HB, Sweet S, Winchester CC, Dent J. Update on the epidemiology of gastro-oesophageal reflux disease: A systematic review. Gut. 2014; 63(6):87180.

3. Jung HK. Epidemiology of gastroesophageal reflux disease in Asia: A systematic review. J Neurogastroenterol Motil. 2011; 17:14-27.

4. Jafri N, Jafri W, Yakoob J, Islam M, Manzoor S, Jalil A, et al. Perception of gastroesophageal reflux disease in urban population in Pakistan. J Coll Physicians Surg Pak. 2005; 15:532-34.

5. Fisichella PM, Patti MG. Gastroesophageal reflux disease (cited, 2017 March 27). Available from url:http://emedicine.medscape.com/article/176595overview.

6. Makmun D. Penyakit refluks gastroesofageal. In: Sudoyo AW, Setyohadi B, Alwi I, Simadibrata M, Setiati S. Buku Ajar Ilmu Penyakit Dalam. Edisi 4. Jakarta: Pusat Penerbitan Departemen IImu Penyakit Dalam FKUI; 2006.p.317-321.

7. Vakil N, van Zanten SV, Kahrilas P, Dent J, Jones R; Global Consensus Group. The Montreal definition and classification of gastroesophageal reflux disease: A global evidence-based consensus. Am J Gastroenterol 2006; 101: 1900-20.

8. Shiwani MH. Treatment of gastroesophageal reflux disease: A call for increase awareness and local research. J Pak Med Assoc 2011; 61: 283-5.

9. Wang R, Zou D, Ma X, Zhao Y, Yan X, Yan H, et al. Impact of gastroesophageal reflux disease on daily life: The systematic investigation of gastrointestinal diseases in China (SILC) epidemiological study. Health Qual Life Outcomes 2010; 8: 128.
10. Stanghellini $\mathrm{V}$, Armstrong $\mathrm{D}$, Monnikes $\mathrm{H}$, Bardhan $\mathrm{KD}$ (2004) Systematic review: Do we need a new gastrooesophageal reflux disease questionnaire? Aliment Pharmacol Ther 19:463-479.

11. A. Kusano $M$, Shimoyama $Y$, Sugimoto $S$ et al. Development and evaluation of FSSG: Frequency scale for the symptoms of GERD. J. Gastroenterol. 2004; 39: 888-91.

12. Lydeard $S$, Jones $R$. Factors affecting the decision to consult with dyspepsia: Comparison of consulters and non consulters. J R Coll Gen Pract 1989; 39: 4958.

13. Kennedy $\mathrm{T}$, Jones $\mathrm{R}$. The prevalence of gastrooesophageal reflux symptoms in a UK population and the consultation behaviour of patients with these symptoms. Aliment Pharmacol Ther 2000; 14: 1589-94.

14. Diaz-Rubio M, Moreno-Elola-Olaso C, Rey E, Locke GR III, Rodriguez-Artalejo F. Symptoms of gastro-oesophageal reflux: Prevalence, severity, duration and associated factors in a Spanish population. Aliment Pharmacol Ther 2004; 19: 95-105.

15. Locke GR III, Talley NJ, Fett SL, Zinsmeister AR, Melton LJ III. Risk factors associated with symptoms of gastroesophageal reflux. Am J Med 1999; 106: 642-9.

16. Klauser AG, Schindlbeck NE, Müller-Lissner SA. Symptoms in gastro-oesophageal reflux disease. Lancet. 1990; 335:205-8.

17. Kaul B, Halvorsen T, Petersen $H$, et al. Gastrooesophageal reflux disease. Scintigraphic, endoscopic, and histologic considerations. Scand J Gastroenterol. 1986; 21:134-8.

18. Wu WC. Ancillary tests in the diagnosis of gastroesophageal reflux disease. Gastroenterol Clin North Am. 1990; 19:671-82.

19. McDonald JWD, Burroughs AK, Feagan BG, Fennetry $M B$. Evidence-based gastroenterology and hepatology, 3rd ed. UK: John Wiley and Sons Ltd; Sep 2010. p. 25.

20. Kusano M, Shimoyama $Y$, Sugimoto $S$, Kawamura O, Maeda M, Minashi K et al. Development and evaluation of FSSG: Frequency scale for the symptoms of GERD. J Gastroenterol 2004; 39:888-91.

21. Jinnai M, Niimi A, Takemura M, Matsumoto H, Konda $Y$, and Mishima M. Gastroesophageal reflux-associated chronic cough in an adolescent and the diagnostic implications: A case report. Cough 2008; 4:5 doi: 10.1186/1745-9974-4-5, (cited, 2017 March 30) available from url: //www.coughjournal.com/content/4/1/5, downloaded on April 2017. 
22. Ndraha S. Combination of PPI with a prokinetic drug in gastroesophageal reflux disease. 2011; 43: 233-36.

23. Miyamoto M, Haruma $\mathrm{K}$, Takeuci $\mathrm{K}$, Kuwabara $\mathrm{M}$. Frequency scale for symptoms of gastroesophageal reflux disease predicts the need for addition of prokinetics to proton pump inhibitor therapy. J Gastroenterol Hepatol 2008; 23:746-51.

24. Faruqui AA. Gastroesophageal reflux disease associated with anxiety: Efficacy and safety of fixed dose combination of amitriptyline and pantoprazole. Gastroenterology Res. 2017; 10(5): 301-304.

25. Bradley LA, Richter JE, Pulliam TJ, et al. The relationship between stress and symptoms of gastroesophageal reflux: The influence of psychological factors. Am J Gastroenterol 1993; 88: 11-9.
26. Baker LH, Lieberman D, Oehlke M. Psychological distress in patients with gastroesophageal reflux disease. Am J Gastroenterol 1995; 90: 1797-803.

27. Naliboff BD, Mayer M, Fass R, et al. The effect of life stress on symptoms of heartburn. Psychol Med 2004; 66: 426-34.

28. Fass R, Naliboff BD, Fass SS, et al. The effect of auditory stress on perception of intraesophageal acid in patients with GERD. Gastroenterology 2008; 134: 696-705.

29. Yang $X J$, Jiang $H M$, Hou $X H$, Song J. Anxiety and depression in patients with gastroesophageal reflux disease and their effect on quality of life. World $\mathrm{J}$ Gastroenterol. 2015; 21(14):4302-4309.

\begin{tabular}{|c|c|c|c|}
\hline \multicolumn{4}{|c|}{ AUTHORSHIP AND CONTRIBUTION DECLARATION } \\
\hline Sr. \# & Author(s) Full Name & Contribution to the paper & Author(s) Signature \\
\hline 1 & Abdul Rabb Bhutto & Data collection and write up. & zew \\
\hline 2 & Amanullah Abbasi & Study design and concept. & \\
\hline 3 & Sultan Ahmed Chandio & Data interpretation. & \\
\hline 4 & Aftab Ahmed Lolai & Literature review. & Afi \\
\hline 5 & Muhammad Arsalan & Data analysis. & \\
\hline
\end{tabular}

